\title{
Wind Loads of Solar Water Heaters: Wind Incidence Effect
}

\author{
Chin-Cheng Chou, Kung-Ming Chung, and Keh-Chin Chang \\ National Cheng Kung University, 2500 Section 1, Chung Cheng South Road, Guiren District, Tainan 711, Taiwan \\ Correspondence should be addressed to Kung-Ming Chung; kmchung@mail.ncku.edu.tw
}

Received 14 July 2014; Accepted 7 October 2014; Published 27 October 2014

Academic Editor: Ujjwal K. Saha

Copyright (C) 2014 Chin-Cheng Chou et al. This is an open access article distributed under the Creative Commons Attribution License, which permits unrestricted use, distribution, and reproduction in any medium, provided the original work is properly cited.

\begin{abstract}
For applications of solar thermal energy, solar water heaters (SWHs) are becoming common. In this study, the effect of a crosswind on the aerodynamic characteristics of residential (an inclined flat plate with a horizontal cylinder) and large-scale SWHs (an inclined flat plate only) is experimentally investigated. The tests are conducted in a low speed wind tunnel and the relative wind direction with respect to the test model, $\beta$, ranges from 0 to $135 \mathrm{deg}$. Measurements of the mean and fluctuating pressures are presented. These results demonstrate that higher suction and fluctuating pressure are observed near the upwind corner, particularly for the test case of $\beta=30 \mathrm{deg}$.
\end{abstract}

\section{Introduction}

The use of renewable energy technologies represents an opportunity to reduce global warming. In this respect, SWHs are rapidly becoming an integral part of worldwide measures to combat the effects of climate change. Previous studies $[1,2]$ found that the wind loads on solar collectors are significantly reduced by the sheltering effect of the first row of collectors and of the building itself. For a residential SWH (an inclined solar collector with a horizontal water storage tank), normal to the direction of smooth uniform wind, the study by Chung et al. $[3,4]$ demonstrated that localized wind loads at a tilt angle $\alpha$ of $15-30 \mathrm{deg}$. are significant near the front edge and reach a minimum value at a distance of approximately onethird of the total length from the leading edge. Reynolds number independence was also noted. For a large-scale SWH (inclined solar collector or flat plate only), Chung et al. $[5,6]$ indicated that there is a higher suction force on the lower surface over the first half of the inclined solar collector and a stronger positive mean longitudinal differential pressure coefficient is observed. Kopp et al. [7] further pointed that the presence of the building changed the aerodynamic loads substantially compared to ground-mounted systems. There is a complex interaction between building generated vortices and the flow induced by solar arrays.

Wind incidence has an important influence on the aerodynamics of bluff bodies [8]. Certain oblique wind directions, $\beta$, correspond to the critical case for wind loads. Wood et al. [9] demonstrated that the orientation of the solar collectors with respect to the wind direction and the proximity of the panels to the leading edge have a significant effect on the pressure distributions measured. Kopp et al. [7] found that the largest wind loads are associated with vortex shedding from in-line solar collectors. The peak system torque is generally observed at angles of approach wind that are close to the diagonals axes of the panel.

This investigation seeks to better understand the effect of a variation in $\beta$ on the mean and fluctuating forces that act on residential and large-scale SWHs on the ground. The experimental setup is described in Section 2. The tilt angle, $\alpha$, of the solar collector is 25 deg., corresponding to the local altitude in Taiwan. In Section 3, surface pressure measurements are presented with a value of $\beta$ that varies from 0 to $135 \mathrm{deg}$. Conclusions are given in Section 4 . The results of this study could provide a reference for the structural design and installation of SWHs.

\section{Experimental Setup}

2.1. Wind Tunnel and Test Model. The experiments were conducted at the wind tunnel, the Architecture and Building Research Institute. The tunnel comprises a honeycomb and three screens and the contraction ratio is 4.71 . The constantarea test section is $2.6 \mathrm{~m}$ (height) $\times 4 \mathrm{~m}$ (width) $\times 36.5 \mathrm{~m}$ 

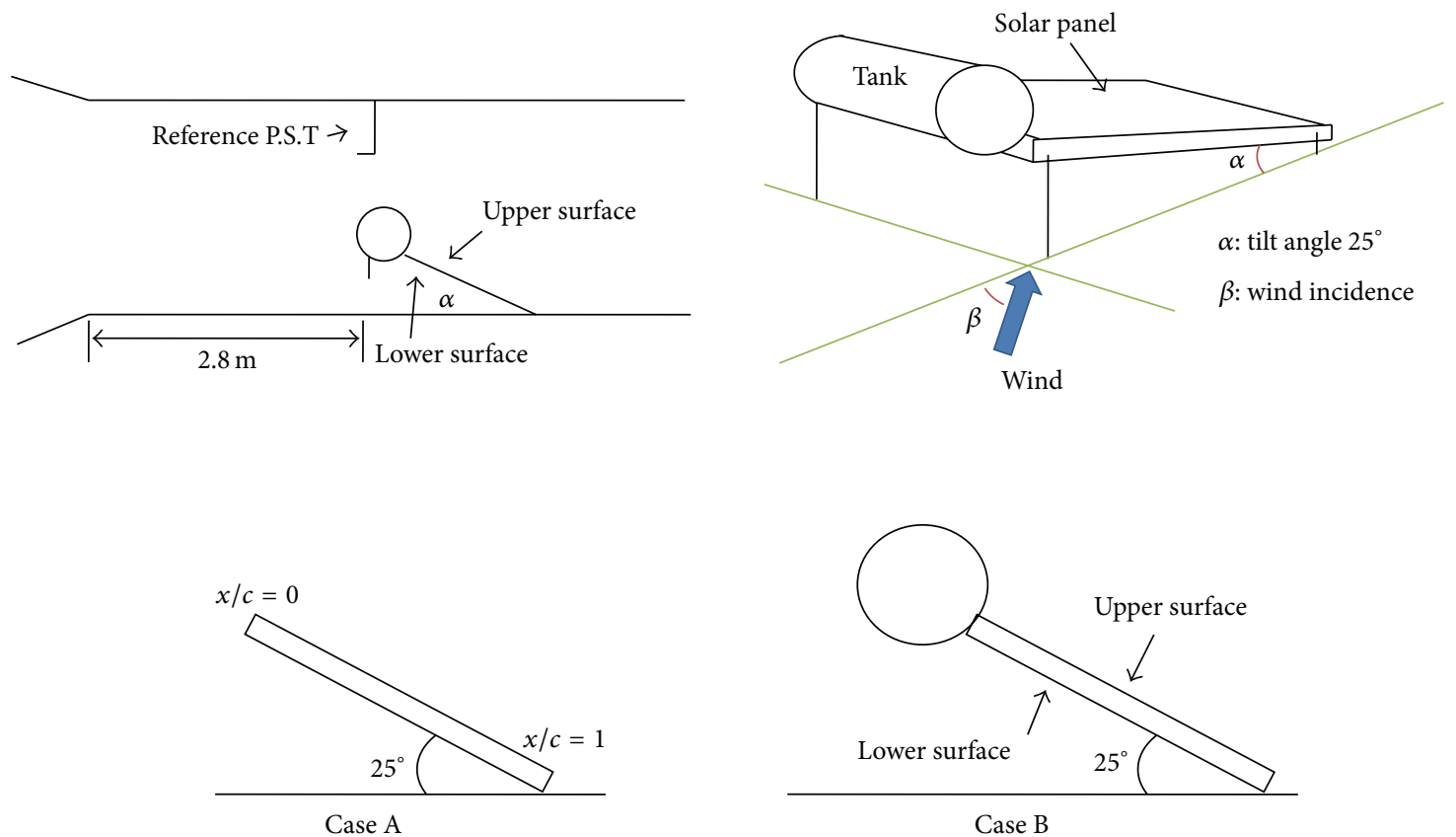

FIgURE 1: A schematic drawing of the wind tunnel and the test models.

(length). A schematic drawing of the test model in the test section is shown in Figure 1, in which almost all SWHs in Taiwan were installed on flat roofs. The turbulence intensity was approximately $0.3 \%$. Note that there are stronger expansion on the upper surface and more positive pressure on the lower surface of an inclined solar collector with an increase in turbulence intensity [4]. Chung et al. [3] indicated Reynolds number independence for the present test configuration. Therefore, the freestream velocity was set at $20.0 \pm 0.1 \mathrm{~m} / \mathrm{s}$, measured using a Pitot-static tube (PST). The front edge of the test model was located $2.8 \mathrm{~m}$ from the inlet of the working section. Two test models were approximately $60 \%$ scaled commercial SWHs (a width/length ratio of 0.5 for a typical solar collector in Taiwan). For a large-scale SWH (Model A), the water storage tanks are separated from the solar collectors, so it is comprised of an inclined solar collector only, which is $120 \mathrm{~cm}$ (length) $\times 60 \mathrm{~cm}$ (width) $\times 5.5 \mathrm{~cm}$ (thickness) at $\alpha=25 \mathrm{deg}$. The Reynolds number, based on the length of the inclined solar collector, was $1.61 \times 10^{6}$. Model B represents a residential SWH (an inclined solar collector with a horizontal cylinder as a water storage tank). The horizontal cylinder is $30 \mathrm{~cm}$ (diameter) $\times 60 \mathrm{~cm}$ (length). It is also known that the wake structure of the cylinder would have influences on the pressure characteristics of the inclined solar collector. An additional Reynolds number, based on the diameter of the cylinder, was $4.03 \times 10^{5}$. The tests involved varying $\beta$ from 0 to $135 \mathrm{deg}$. Note that the lower surface of the inclined solar collector faces the wind direction for the test case, $\beta=0 \mathrm{deg}$. The blockage ratio ranged from 2.5 to $4.5 \%$, so there are no blockage corrections applied to the present results. For the surface pressure measurements, it is known that there are strong pressure gradients (flow separation and reattachment) near the front edge of the inclined solar collector. Therefore,

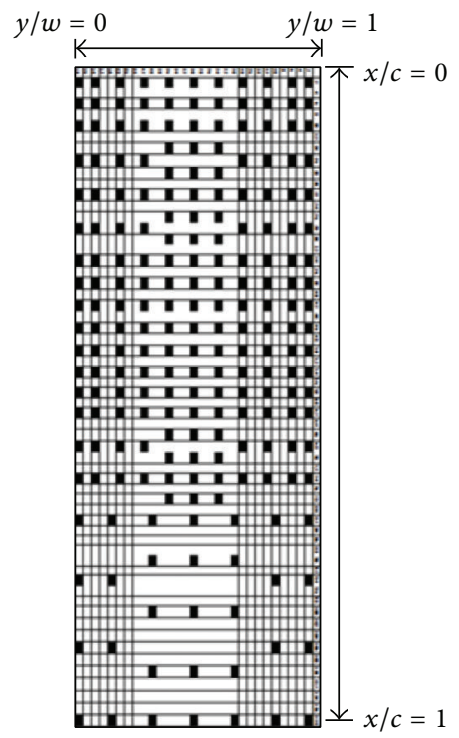

FIGURE 2: A schematic drawing of the pressure taps.

92\% pressure taps were machined on the first two-thirds of the upper and lower plate surfaces, as shown in Figure 2. The front edge of the inclined solar collector corresponds to streamwise distance of $x / c=0$. Note that there were no pressure taps on the horizontal cylinder.

2.2. Measurement Techniques. The measurement of the mean and fluctuating surface pressures was performed using seven Scanivalve multichannel modules (Model ZOC 33/64Px 64-port), which contained differential pressure transducers (Model RAD3200). The full-scale range of the sensors is 


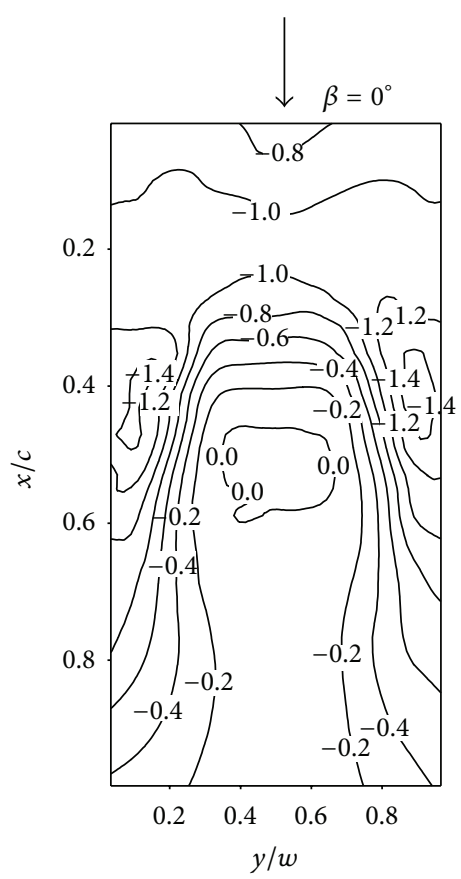

(a)

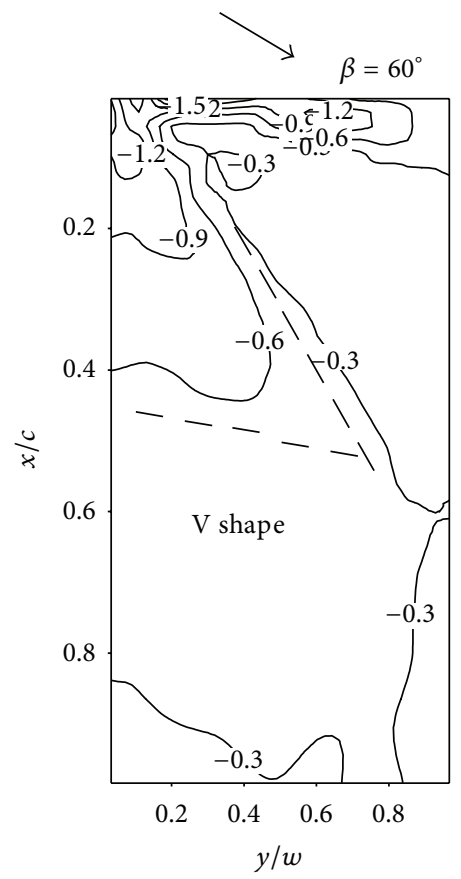

(d)

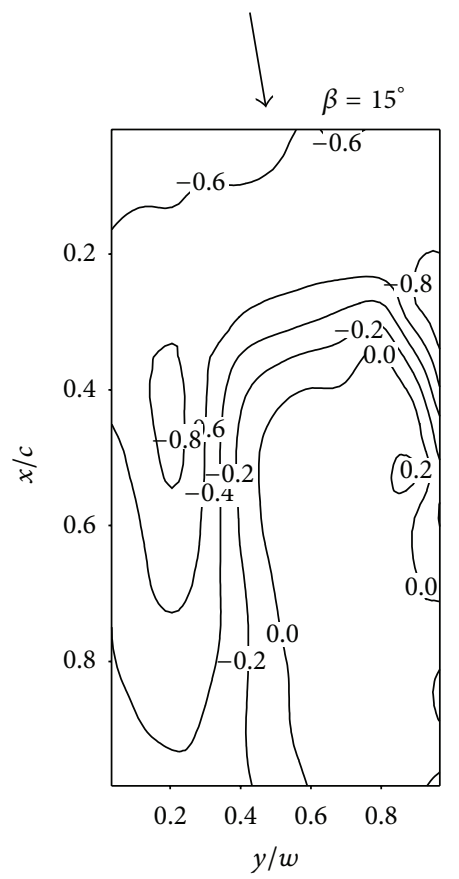

(b)

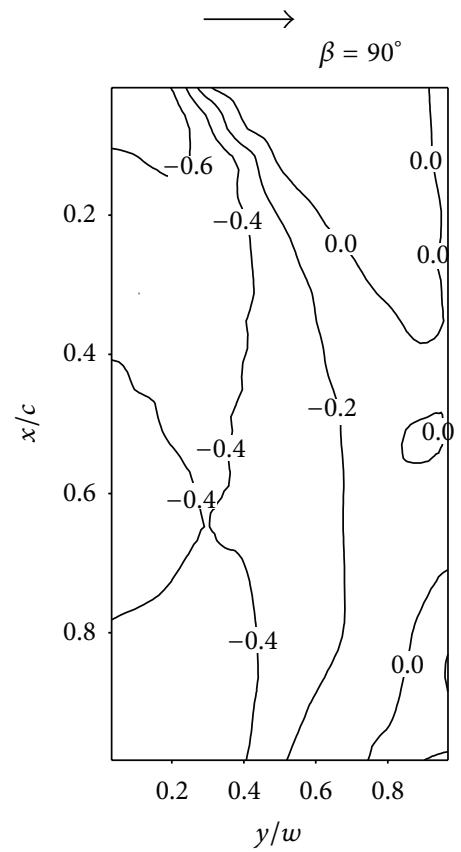

(e)

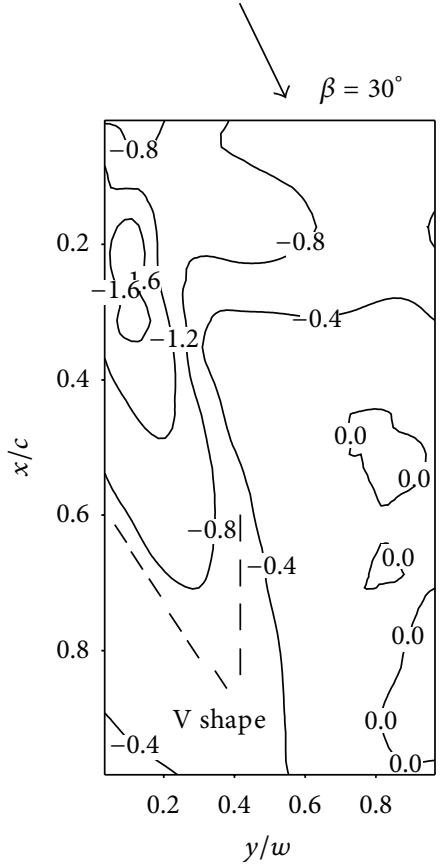

(c)

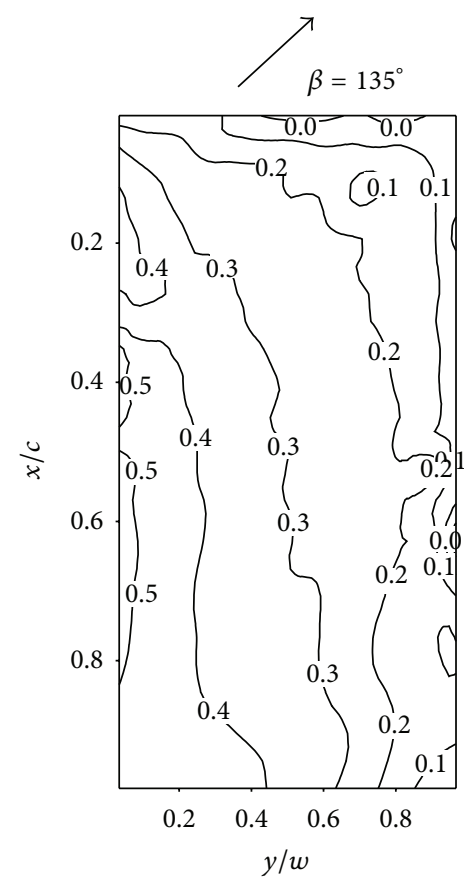

(f)

Figure 3: Contour plots of $C_{p \text {,up }}$ for Case A; (a) $\beta=0$ deg., (b) $\beta=15$ deg., (c) $\beta=30$ deg., (d) $\beta=60$ deg., (e) $\beta=90$ deg., and (f) $\beta=135$ deg.

$\pm 2,490 \mathrm{~Pa}$ (or \pm 10 inch $\mathrm{H}_{2} \mathrm{O}$ ) and their accuracy is $\pm 0.15 \%$ of the full scale. Irwin et al. [10] demonstrated that the effect of the phase distortion alone on the measured peak pressures is small for tubes of the order of $60 \mathrm{~cm}$, so the pressure modules were placed inside the model. 440 pressure taps were connected to $1.1 \mathrm{~mm}$ internal diameter flexible polyvinyl chloride (pvc) tubing (30 cm long). The sampling rate used for all the test cases was $256 \mathrm{~Hz}$ and each record contained 40,960 data points. The mean surface pressures were nondimensionalized in terms of the values of the static pressure, $p_{\infty}$, and the dynamic pressure, $q$, of the incoming flow, in which $C_{p}=(p-$ $\left.p_{\infty}\right) / q$. The fluctuating pressure coefficient, $C_{\sigma p}$, is given as $\sigma_{p} / q$, where $\sigma_{p}$ is standard deviation of surface pressure. The lift coefficient (positive downward), $C_{L}\left((1 / q A) \int_{A} \Delta C_{p} d A\right)$, 


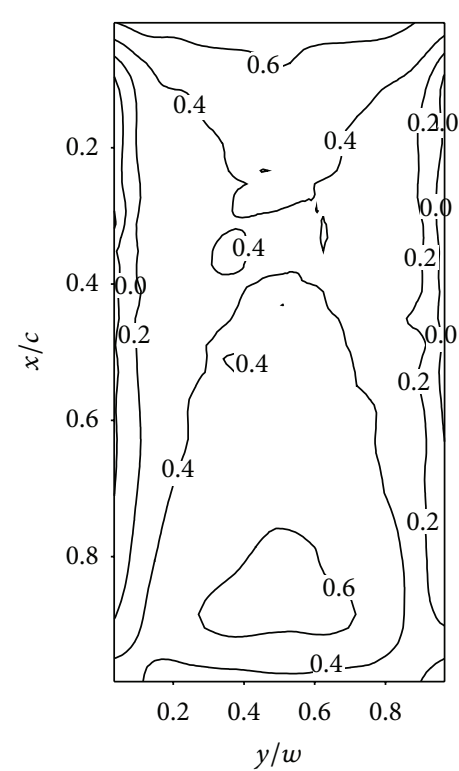

(a)

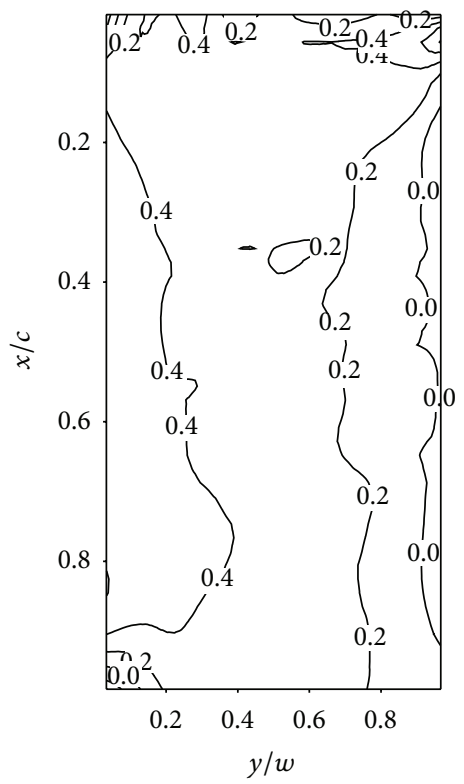

(d)

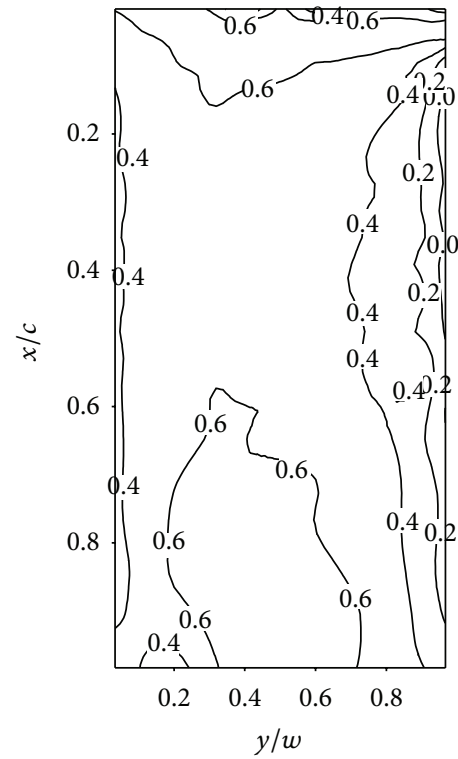

(b)

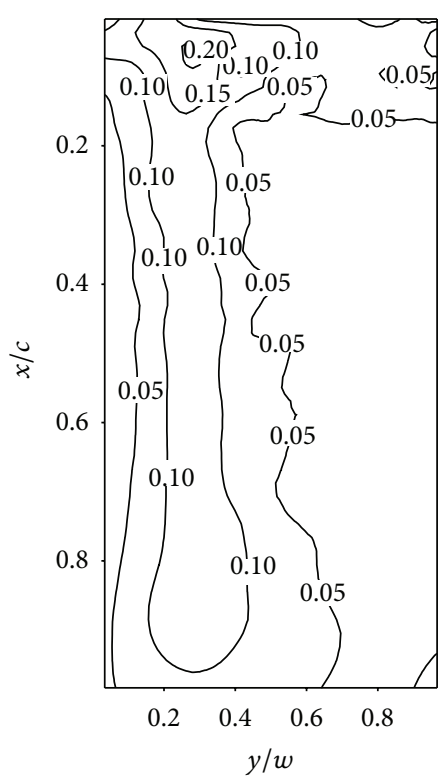

(e)

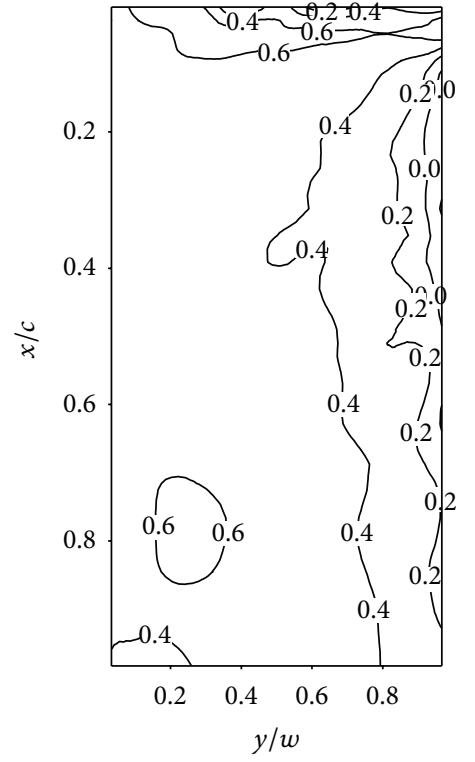

(c)

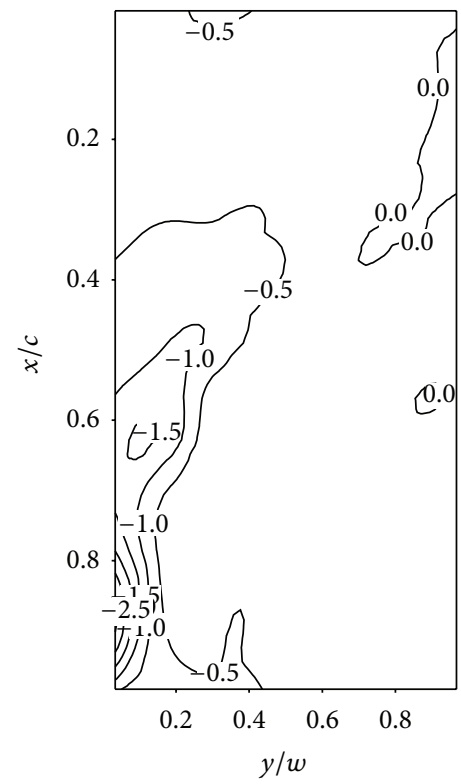

(f)

Figure 4: Contour plots of $C_{p \text {,low }}$ for Case A; (a) $\beta=0$ deg., (b) $\beta=15$ deg., (c) $\beta=30$ deg., (d) $\beta=60$ deg., (e) $\beta=90$ deg., and (f) $\beta=135$ deg.

is evaluated by the integration of the differential mean surface pressure distributions $\left(\Delta C_{p}=C_{p \text {,up }}-C_{p, \text { low }}\right)$ on the inclined solar collector.

\section{Results and Discussion}

3.1. Mean Pressure Distributions. For Case A, the distribution of the mean surface pressure coefficient on the upper surface $\left(C_{p \text {,up }}\right)$ of the inclined solar collector at $\beta=0,15,30,60$, 90 and $135 \mathrm{deg}$. is shown in Figure 3. The front edge of the inclined solar collector corresponds to $x / c=0$ and $y / w$ is the spanwise distance from the left edge, facing wind direction.
For the test case of $\beta=0$ deg. (Figure 3(a)), the mean surface pressure coefficients are negative, as expected. A symmetric pressure distribution, with reference to the centerline of the inclined solar collector, is observed. Chung et al. [5] found that the separation region on the upper surface of an inclined solar collector appears near the front edge and that there are vortices near the side edges, which results in a relatively larger negative mean surface pressure coefficient. After the pressure coefficient decreases gradually toward downstream from the leading edge, a minimum of 1.0 at $x / c=0.15$ is observed. Then it increases rapidly to 0 until $x / c \approx 0.5$ and keeps a constant value of 0.2 toward the downstream edge 


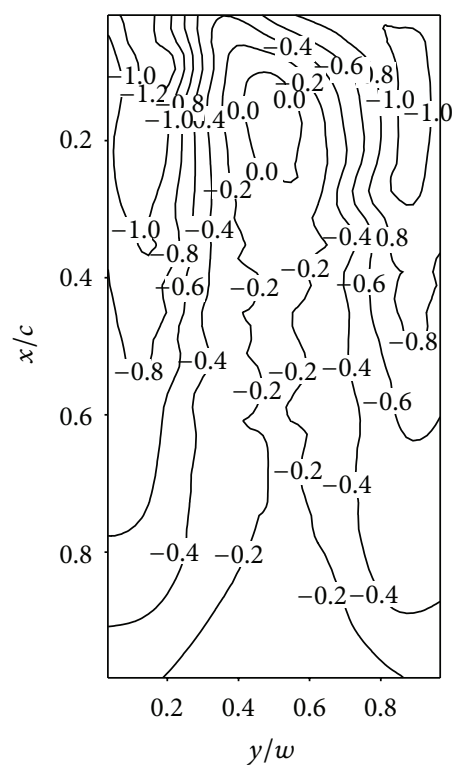

(a)

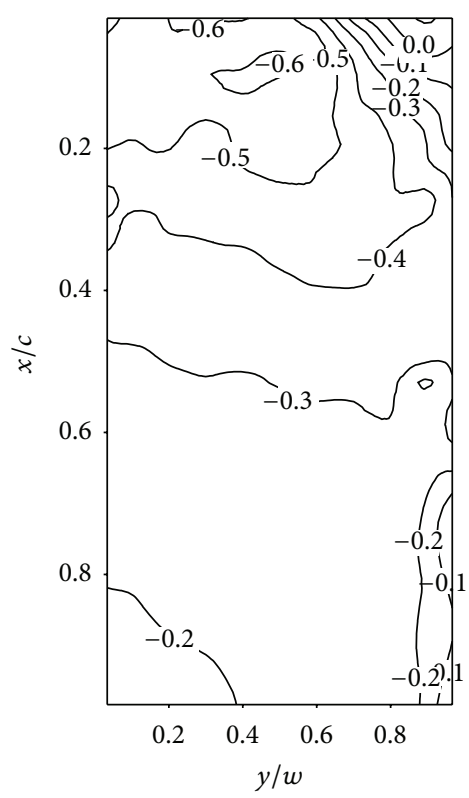

(d)

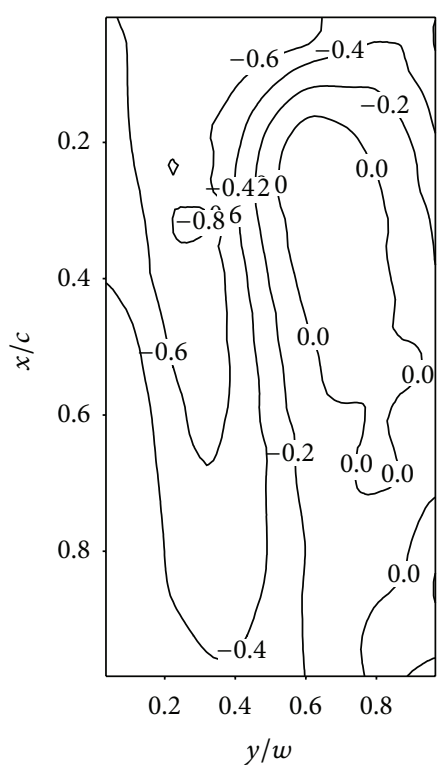

(b)

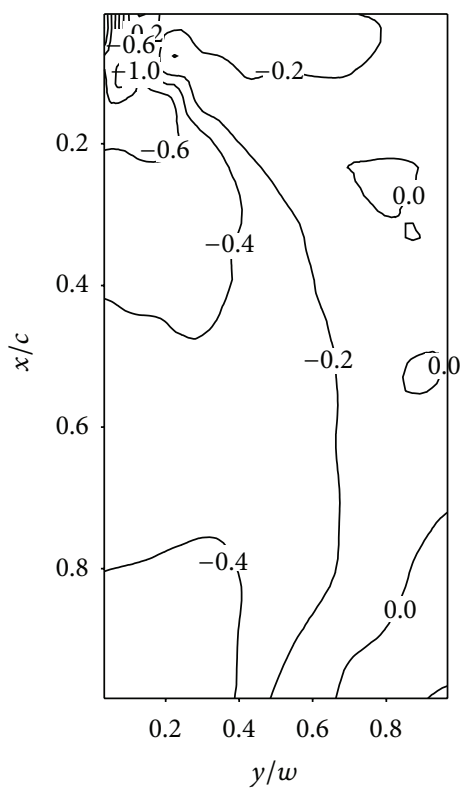

(e)

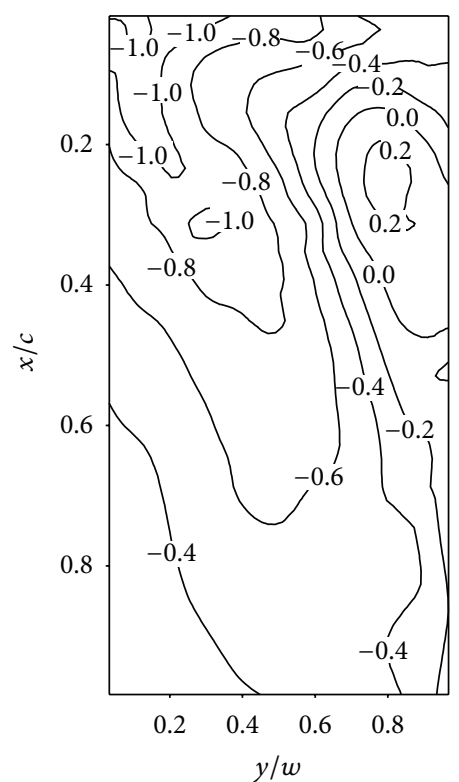

(c)

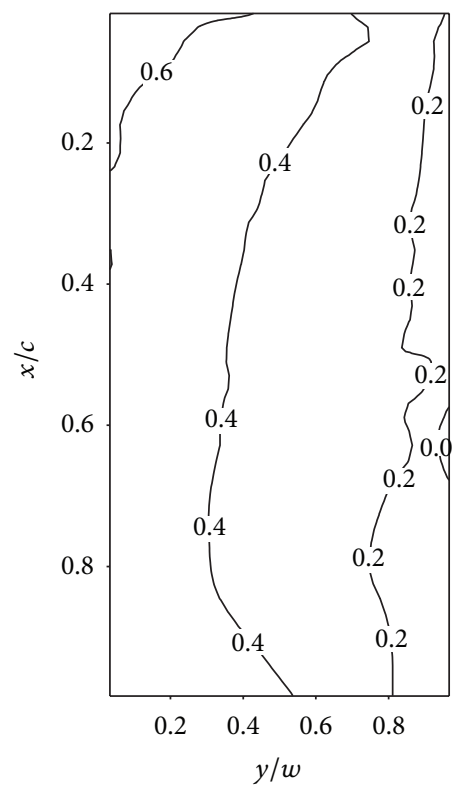

(f)

Figure 5: Contour plots of $C_{p \text {,up }}$ for Case B; (a) $\beta=0$ deg., (b) $\beta=15$ deg., (c) $\beta=30$ deg., (d) $\beta=60$ deg., (e) $\beta=90$ deg., and (f) $\beta=135 \mathrm{deg}$.

along the center line. On the other hand, the relatively large suction of which the pressure coefficient is -1.4 is observed near both side edges at $x / c=0.4$. When $\beta$ increases, the mean surface pressure pattern changes significantly. At a slight wind incidence ( $\beta=15 \mathrm{deg}$.), the symmetry of the mean surface pressure pattern is shifted in a counterclockwise direction (or along approach wind), as shown in Figure 3(b). V-shaped stripes of high suction are observed on the left half of the inclined solar collector; these might correspond to the conical vortices that are found on a building's roof when the wind incidence is oblique [11]. The results also agree with the numerical study by Chuang [12], in which there are formation of corner vortices at the front left edge and circulation at the front right edge for an inclined flat plate at $\beta=15 \mathrm{deg}$. At $\beta=30 \mathrm{deg}$., as shown in Figure 3(c), the peak $C_{p \text {,up }}$ value tends toward a value of -1.6 and the region of high suction moves to the windward corner $(x / c \approx 0.3$ and $y / w \approx 0.1)$. V-shaped stripes with a more negative $C_{p \text {,up }}$ or higher suction levels than that at $\beta=15 \mathrm{deg}$. are observed. There is upstream movement of reattachment location for an inclined flat plate with increasing $\beta$ [12]. The region of high suction is narrower and closer to the upwind corner at the left side edge for the test case of $\beta=60 \mathrm{deg}$. (Figure 3(d)), corresponding to breakdown of corner vortices. At $\beta=$ 


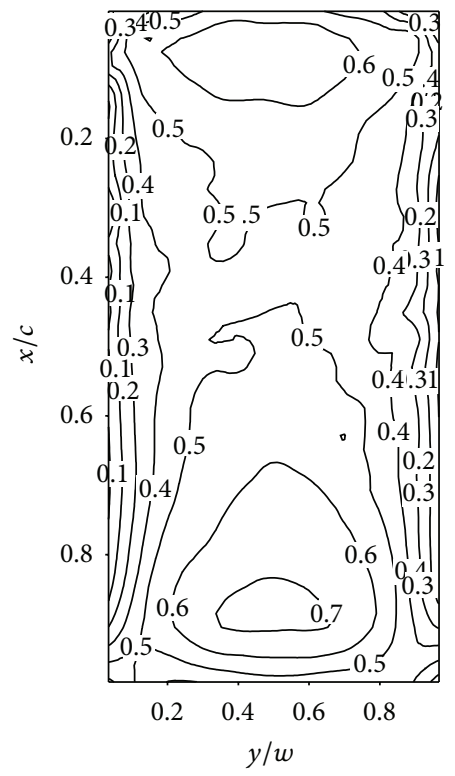

(a)

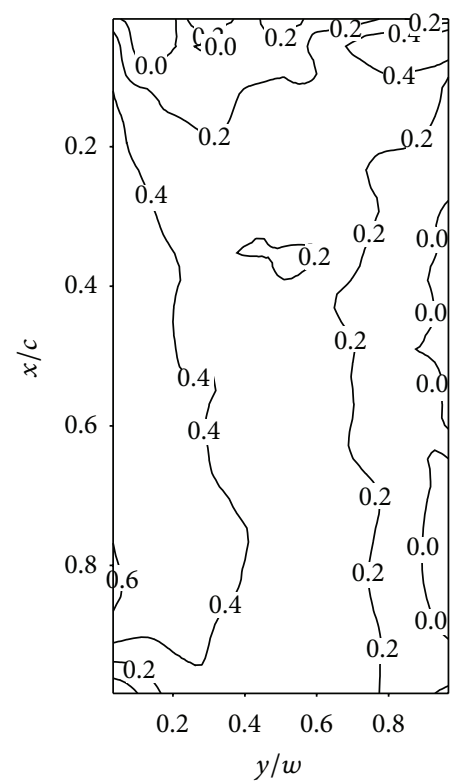

(d)

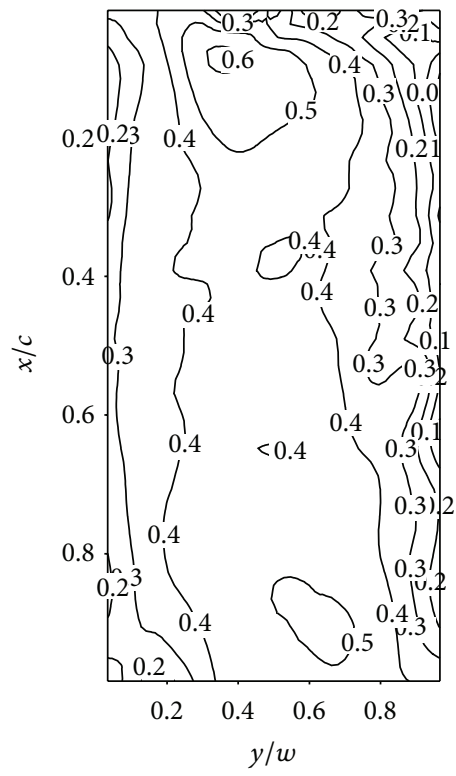

(b)

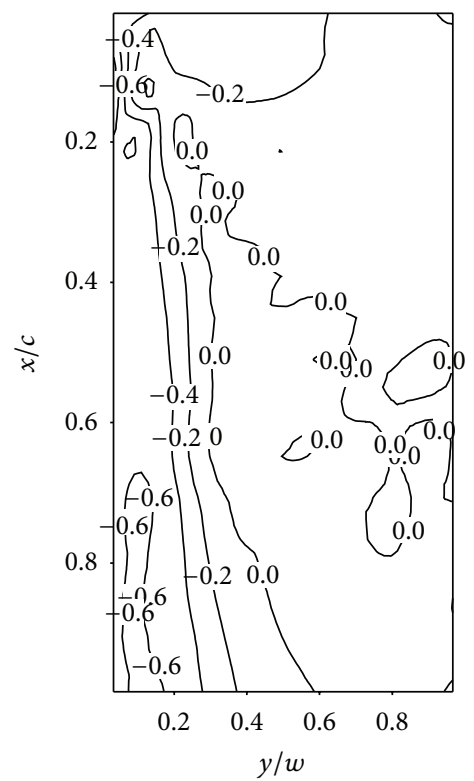

(e)

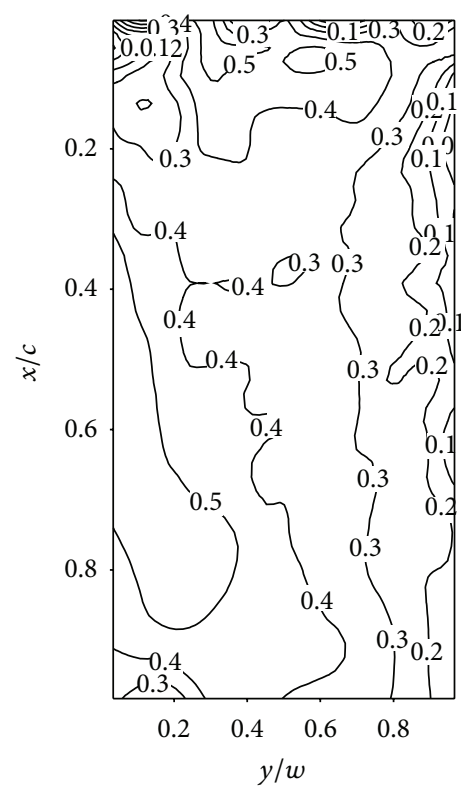

(c)

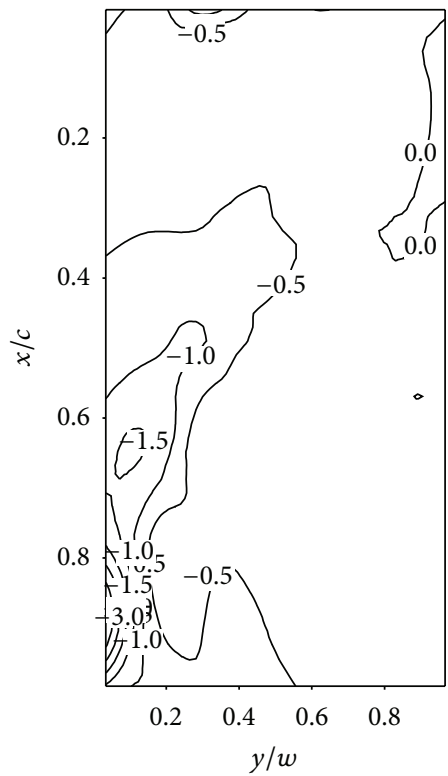

(f)

Figure 6: Contour plots of $C_{p \text {,low }}$ for Case B; (a) $\beta=0$ deg., (b) $\beta=15$ deg., (c) $\beta=30$ deg., (d) $\beta=60$ deg., (e) $\beta=90$ deg., and (f) $\beta=135$ deg.

90 deg.,wind blows along the inclined solar collector's span. A relatively symmetric pressure pattern is observed in the spanwise direction, as shown in Figure 3(e). When wind blows over the lower surface of the inclined solar collector ( $\beta=135$ deg.), the pressure coefficients are positive on the upper surface. The high suction pressure region at the upwind corner is not observed.

The mean pressure distributions on the lower surface $\left(C_{p, \text { low }}\right)$ for Case A are shown in Figure 4 . At $\beta=0$ deg. (Figure 4(a)), the pressure is positive, so it acts in the upward direction. The highest positive pressure coefficient $\left(C_{p \text {,low }} \approx\right.$ $0.6)$ is observed near the front and rear edges. This is caused by the blocking effect of the inclined solar collector. When the wind is at a slightly oblique angle, $\beta=15 \mathrm{deg}$. (Figure $4(\mathrm{~b})$ ), the pressure pattern shifts in a counterclockwise direction, which is similar to the observation for the upper surface pressure pattern. Chuang [12] indicated that there is less blocking effect on the lower surface of an inclined solar collector with increasing $\beta$. The higher positive pressure region is expanded at the front and rear of the inclined solar collector, resulting in a higher bending moment for the inclined solar collector than for $\beta=0 \mathrm{deg}$. The largest positive values decrease when $\beta$ increases, as shown in Figures 4(d) and $4(\mathrm{e})$. Further, the distribution of the pressure coefficients 


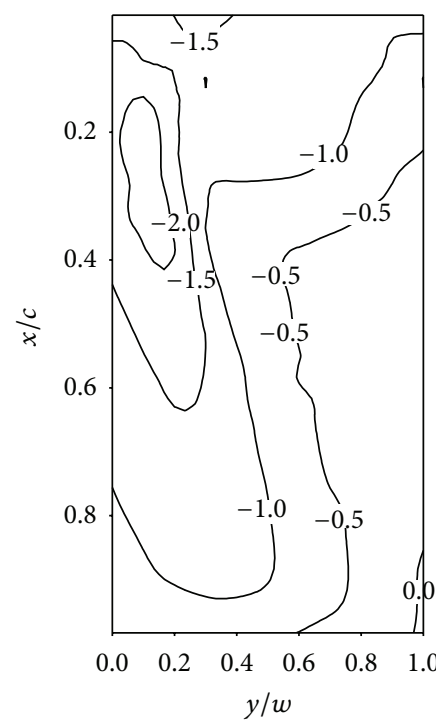

(a)

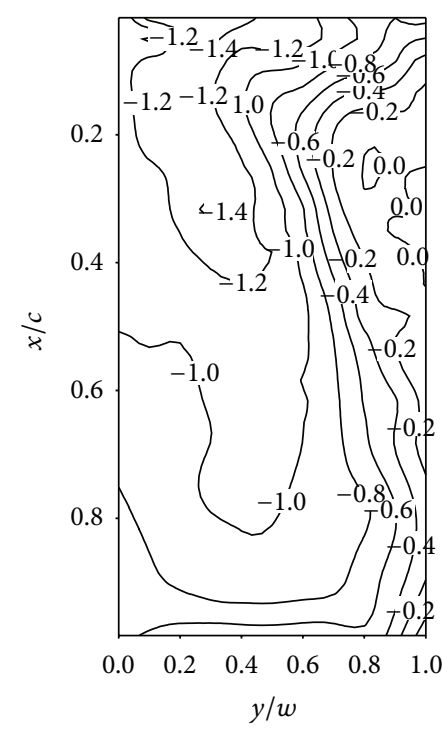

(b)

Figure 7: Contour plots of $\Delta C_{p}$ at $\beta=30$ deg.; (a) Case A and (b) Case B.

at $\beta=135 \mathrm{deg}$. shows a region of negative pressure coefficient along the left edge. The largest negative pressure coefficient has a value of -2.5 , at the left corner, near the rear edge.

The $C_{p \text {,up }}$ distributions for Case B are shown in Figure 5. At $\beta=0-60$ deg., the presence of the horizontal cylinder results in less negative pressure coefficient (or decreased separation strength) near the front edge. For example, the lowest $C_{p \text {,up }}$ values at $\beta=0$ deg. are -1.4 and -1.2 , for Case $\mathrm{A}$ and Case B, respectively. It is also noted that the location of side-edge vortices moves upstream. There is more negative pressure coefficient for $\beta=15 \mathrm{deg}$. than that for $\beta=30 \mathrm{deg}$. near the left upwind corner, which indicates greater suction force. At $\beta=90$ and 135 deg., the $C_{p \text {,up }}$ distributions are similar to those for Case A. On the lower surface, the $C_{p \text {,low }}$ distributions are shown in Figure 6. In comparison with Case $A$, it can be seen that the horizontal cylinder has only a minor influence on $C_{p \text {,low }}$ near the front edge, for all test cases.

The surface pressure patterns on the upper and lower surface of the inclined solar collector demonstrate that there are higher wind loads at smaller oblique angle of wind incidence, corresponding to higher suction force on the upper surface. At $\beta=30 \mathrm{deg}$., the distributions of the differential pressure coefficient, $\Delta C_{p}$, for Cases $\mathrm{A}$ and $\mathrm{B}$ are shown in Figure 7. The peak values of $\Delta C_{p}$ near the upwind left corner are -2.0 and -1.4 for Case $A$ and Case $\mathrm{B}$, respectively. This demonstrates that the lift force on the inclined solar collector is higher when the horizontal cylinder is present (Case $\mathrm{B})$.

3.2. Characteristics of Surface Pressure Fluctuations. It is known that fluctuating loads affect the safety and the fatigue life of structures [13]. For Case A, the distributions of the fluctuating pressure coefficient on the upper surface, $C_{\sigma p \text {, up' }}$, for all test cases, are shown in Figure 8. At $\beta=0$ deg., there are two regions of greater pressure fluctuations, caused by the interaction of the front-edge separation bubble and the sideedge vortices. When $\beta$ increases $(\beta=15-60 \mathrm{deg}$.), the peak value for $C_{\sigma p \text {,up }}$ is observed near the upwind left corner. This pattern reveals the possible presence of conical vortices on an inclined solar collector at oblique wind incidence. This is more evident than what is shown by the $C_{p \text {,up }}$ distribution in Figure 3. Note that the highest $C_{\sigma p \text {,up }}$ value of 0.5 occurs at $\beta=30$ deg. When $\beta=90$ and 135 deg., the inclined solar collector is subject to smaller pressure fluctuations than at smaller oblique angles of wind incidence.

For Case $B$, examples of $C_{\sigma p \text {,up }}$ contours $(\beta=0,30$ and 60 deg.) are shown in Figure 9. It is seen that the presence of the horizontal cylinder results in smaller pressure fluctuations. At $\beta=0$ deg., the peak value of $C_{\sigma p \text {,up }}$ is approximately 0.25 , which is less than the pressure fluctuations for Case A $(=0.40)$. In addition, the two regions of high pressure fluctuations disappear, because of the effect of the horizontal cylinder on the separation, near the front edge. Figures 9(b) and 9(c) also show smaller pressure fluctuations due to weaker conical vortices.

3.3. Lift Forces on an Inclined Flat Plate. The lift coefficient, $C_{L}$, of the inclined solar collector is evaluated by integrating the $\Delta C_{p}$ distribution. The results are shown in Figure 10. It is seen that the magnitude of $C_{L}$ varies with $\beta$. For Case $A, C_{L}$ has almost the same magnitude at $\beta=0$ and $30 \mathrm{deg}$. A larger value is observed at $\beta=15 \mathrm{deg}$. At $\beta>60 \mathrm{deg}$., it appears that $C_{L}$ increases linearly with $\beta$. Note that the lift force is close to zero at $\beta=90 \mathrm{deg}$. For Case $B$, the variation in $C_{L}$ with $\beta$ follows a similar trend as that for Case A. However, the value of $C_{L}$ is higher. Further, an increase in the lift force due to the presence of a horizontal cylinder is of interest. The data are shown in Figure 11. At angles of wind incidence between $\beta=0$ and 30 deg., $\Delta C_{L}\left(=C_{L \text {,Case } \mathrm{A}}-C_{L \text {,Case B }}\right)$ decreases 


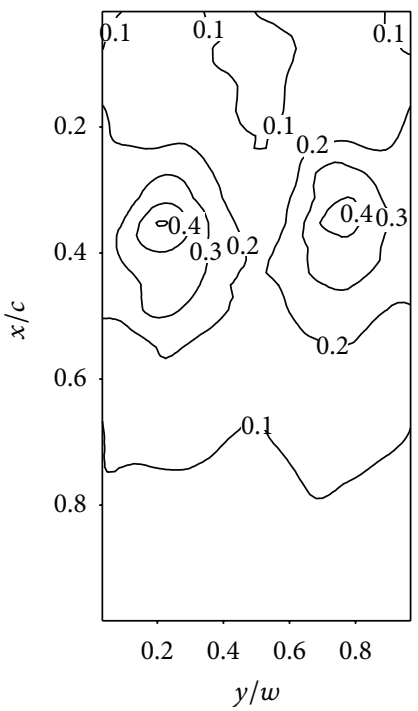

(a)

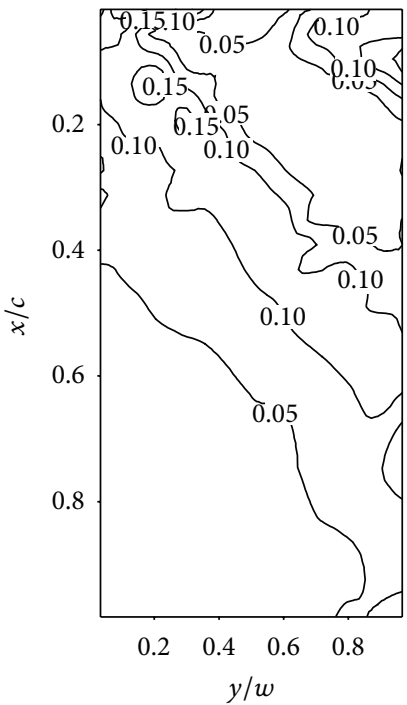

(d)

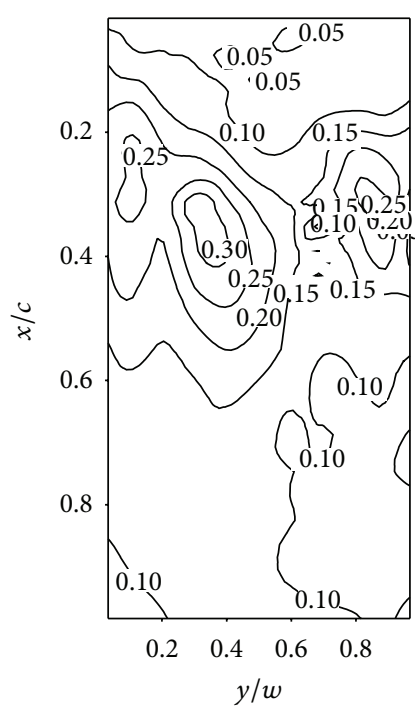

(b)

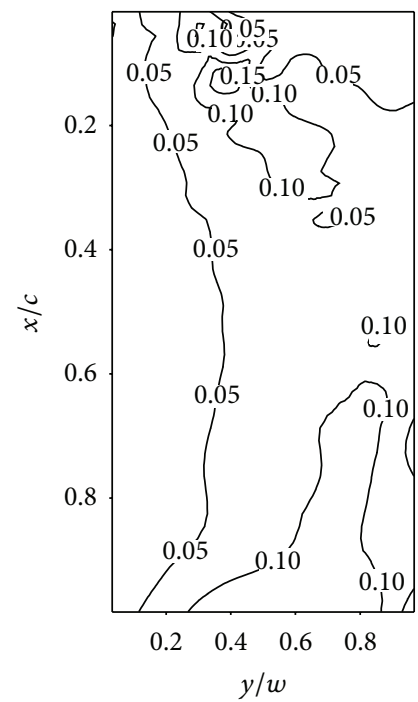

(e)

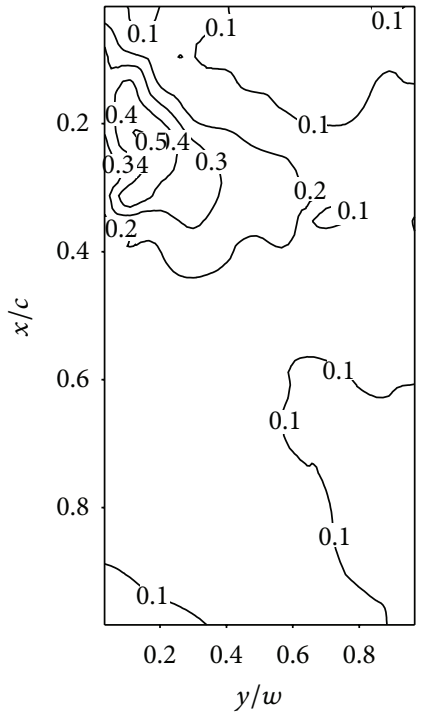

(c)

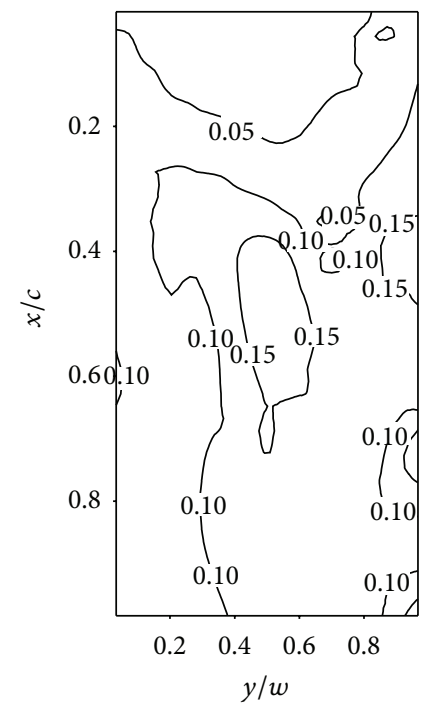

(f)

Figure 8: Contour plots of $C_{\sigma p \text {,up }}$ for Case $A$; (a) $\beta=0$ deg., (b) $\beta=15$ deg., (c) $\beta=30$ deg., (d) $\beta=60$ deg., (e) $\beta=90$ deg., and (f) $\beta=135 \mathrm{deg}$.

as $\beta$ is increased. The effect of the horizontal cylinder is less significant when $\beta$ is increased. It is also seen that the value of $\Delta C_{L}$ has almost the same magnitude at $\beta=30$ and $60 \mathrm{deg}$. When wind blows along the inclined solar collector's span $(\beta=90 \mathrm{deg}$.$) , the value of \Delta C_{L}$ is close to zero. At $\beta=$ 135 deg., the value of $\Delta C_{L}$ becomes negative. There is a lower value of lift force for Case $B$.

\section{Conclusions}

This study investigates the effect of wind incidence $(\beta=$ $0-135$ deg.) on the mean and fluctuating pressures on an inclined solar collector on the ground, with and without the presence of a horizontal cylinder. For the test case of an inclined solar collector only, there are regions of higher suction on the upper surface near the windward corner, for values of $\beta$ between 15 and $60 \mathrm{deg}$. The higher positive pressure region is expanded at the front and rear of the lower surface, which results in a higher bending moment for an inclined flat plate than that at $\beta=0 \mathrm{deg}$. When wind blows over the lower surface $(\beta=135 \mathrm{deg}$.), a region of negative pressure coefficient along the left edge on the lower surface is observed. The fluctuating pressure pattern reveals the possible presence of conical vortices, particularly at $\beta=30 \mathrm{deg}$. The presence of a horizontal cylinder results in less negative pressure coefficient and smaller pressure fluctuations on the upper surface near the front edge. There is a minor influence on the pressure contours on the lower surface and a minor variation in the lift force on the inclined 


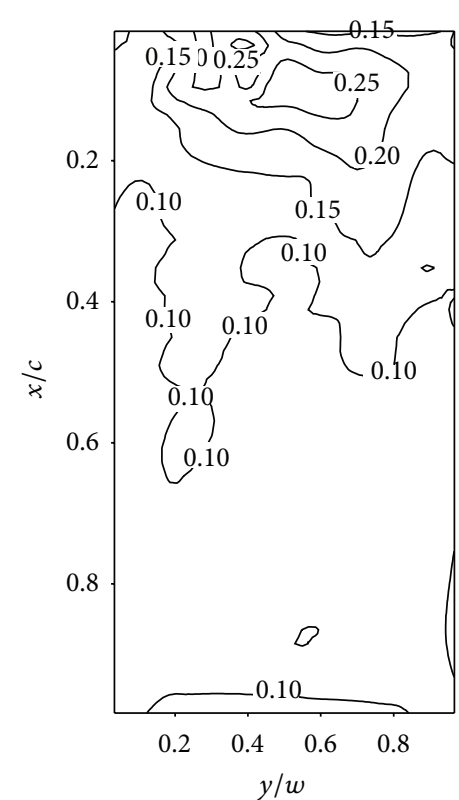

(a)

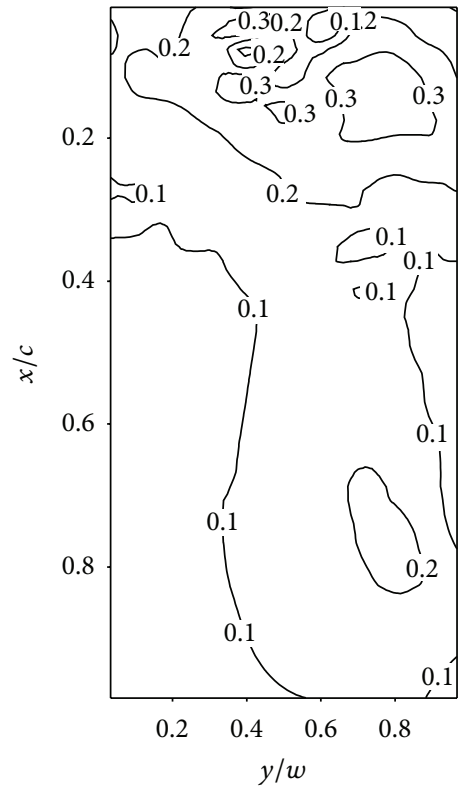

(b)

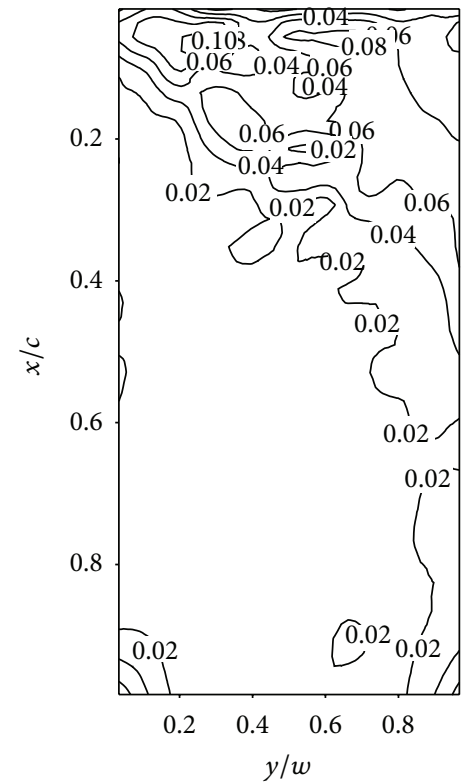

(c)

Figure 9: Contour plots of $C_{\sigma p \text {,up }}$ for Case B; (a) $\beta=0$ deg., (b) $\beta=30$ deg., and (c) $\beta=60$ deg.

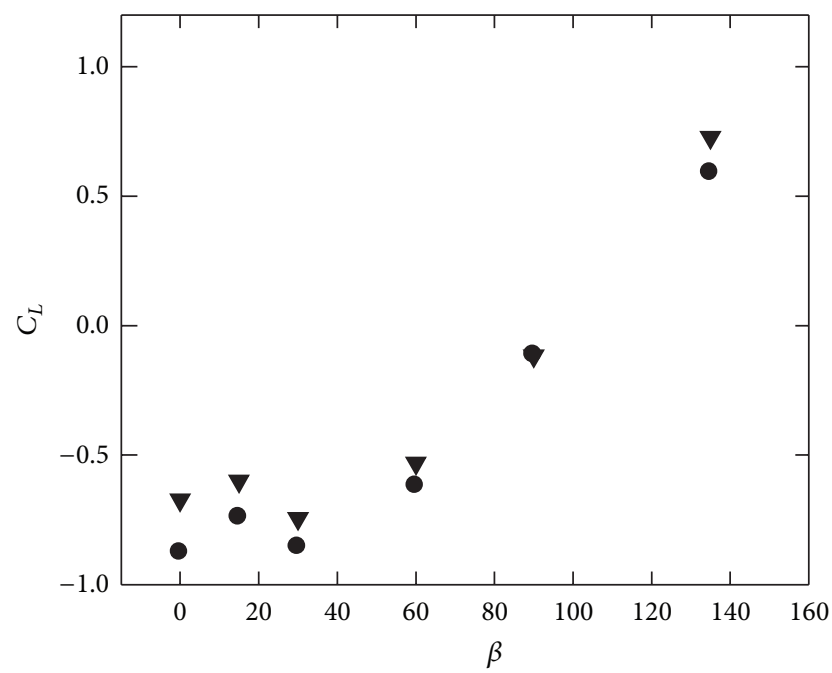

- Case A

$\nabla$ Case B

FIGURE 10: Lift coefficient.

solar collector at $\beta<60 \mathrm{deg}$. With an increase in the value of $\beta$, the lift coefficient increases linearly. The presence of a horizontal cylinder results in an increase in the lift force.

\section{Nomenclature}

A: $\quad$ Area of solar collector

$c$ : $\quad$ Length of solar collector

$C_{p}: \quad$ Pressure coefficient, $\left(p-p_{\infty}\right) / q$

$C_{p, \text { low }}$ : Pressure coefficient on lower surface

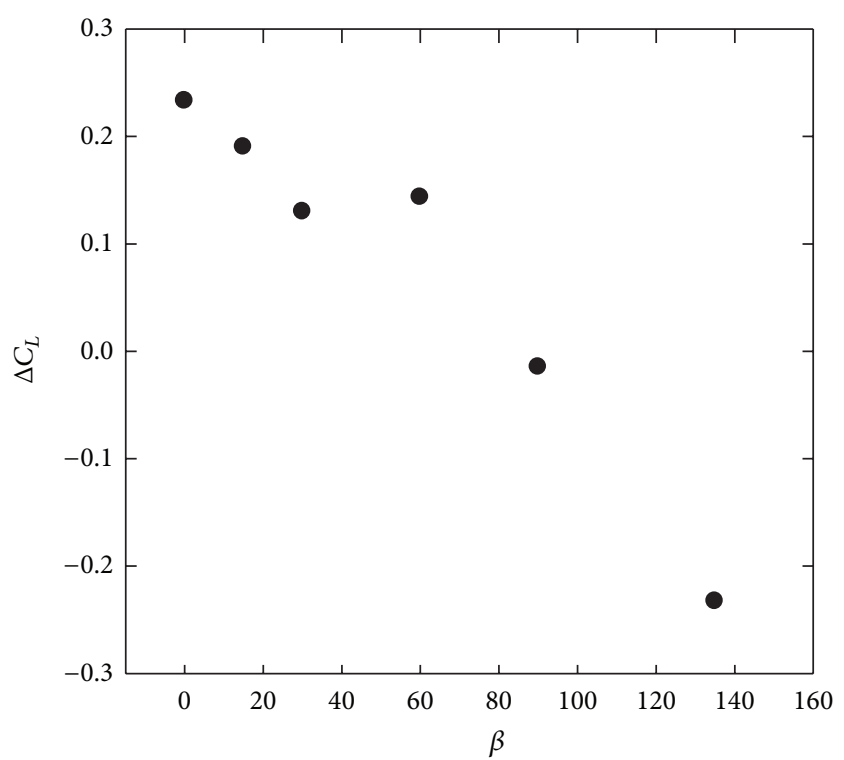

FIGURE 11: The variation in the lift coefficient with and without a horizontal cylinder.

$C_{p, \text { up }}: \quad$ Pressure coefficient on upper surface

$C_{L}: \quad$ Lift coefficient, $\Delta C_{p} /(q A)$

$C_{\sigma p}: \quad$ Fluctuating pressure coefficient, $\sigma_{p} / q$

$C_{\sigma p \text {,low }}$ : Fluctuating pressure coefficient on lower surface

$C_{\sigma p \text {,up }}$ : Fluctuating pressure coefficient on upper surface

$p: \quad$ Mean surface pressure

$p_{\infty}: \quad$ Freestream static pressure 


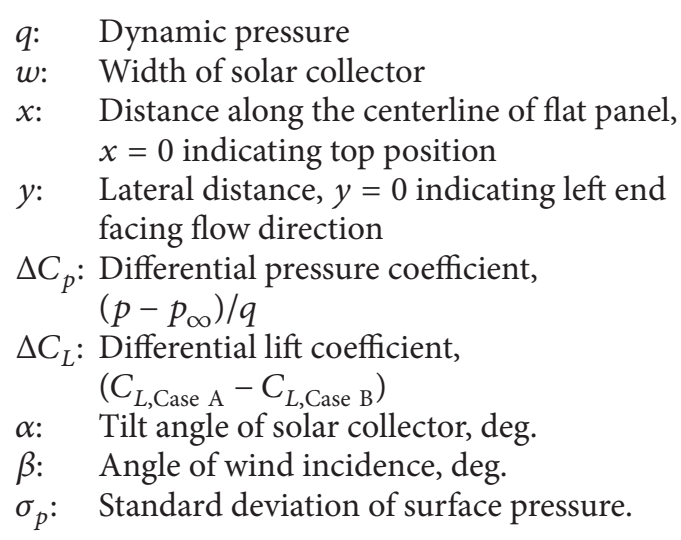

\section{Conflict of Interests}

The authors declare that there is no conflict of interests regarding the publication of this paper.

\section{Acknowledgment}

This work was under the support by the Bureau of Energy, Ministry of Economic Affairs, Taiwan.

\section{References}

[1] A. Radu, E. Axinte, and C. Theohari, "Steady wind pressures on solar collectors on flat-roofed buildings," Journal of Wind Engineering and Industrial Aerodynamics, vol. 23, no. 1-3, pp. 249-258, 1986.

[2] A. Radu and E. Axinte, "Wind forces on structures supporting solar collectors," Journal of Wind Engineering and Industrial Aerodynamics, vol. 32, no. 1-2, pp. 93-100, 1989.

[3] K. Chung, K. Chang, and Y. Liu, "Reduction of wind uplift of a solar collector model," Journal of Wind Engineering and Industrial Aerodynamics, vol. 96, no. 8-9, pp. 1294-1306, 2008.

[4] K.-M. Chung, C.-C. Chou, K.-C. Chang, and Y.-J. Chen, "Wind loads on a residential solar water heater," Journal of the Chinese Institute of Engineers, vol. 36, no. 7, pp. 870-877, 2013.

[5] K.-M. Chung, K.-C. Chang, and C.-C. Chou, "Wind loads on residential and large-scale solar collector models," Journal of Wind Engineering and Industrial Aerodynamics, vol. 99, no. 1, pp. 59-64, 2011.

[6] K. M. Chung, C. C. Chou, K. C. Chang, and Y. J. Chen, "Effect of a vertical guide plate on the wind loading of an inclined flat plate," Wind and Structures, vol. 17, no. 5, pp. 537-552, 2013.

[7] G. A. Kopp, D. Surry, and K. Chen, "Wind loads on a solar array," Wind and Structures, vol. 5, no. 5, pp. 393-406, 2002.

[8] M. Gohlke, J. F. Beaudoin, M. Amielh, and F. Anselmet, "Experimental analysis of flow structures and forces on a 3Dbluff-body in constant cross-wind," Experiments in Fluids, vol. 43, no. 4, pp. 579-594, 2007.

[9] G. S. Wood, R. O. Denoon, and K. C. S. Kwok, "Wind loads on industrial solar panel arrays and supporting roof structure," Wind \& Structures, vol. 4, no. 6, pp. 481-494, 2001.

[10] H. P. A. H. Irwin, K. R. Cooper, and R. Girard, "Correction of distortion effects caused by tubing systems in measurements of fluctuating pressures," Journal of Wind Engineering and Industrial Aerodynamics, vol. 5, no. 1-2, pp. 93-107, 1979.
[11] H. Kawai and G. Nishimura, "Characteristics of fluctuating suction and conical vortices on a flat roof in oblique flow," Journal of Wind Engineering and Industrial Aerodynamics, vol. 60, no. 1-3, pp. 211-225, 1996.

[12] C. C. Chuang, Numerical studies of the lift and drag of a solar collector with wind incidence [M.S. thesis], Department of Aeronautics and Astronautics, National Cheng Kung University, Tainan, Taiwan, 2013.

[13] J. D. Holmes, "Fatigue life under along-wind loading: closedform solutions," Engineering Structures, vol. 24, no. 1, pp. 109$114,2002$. 

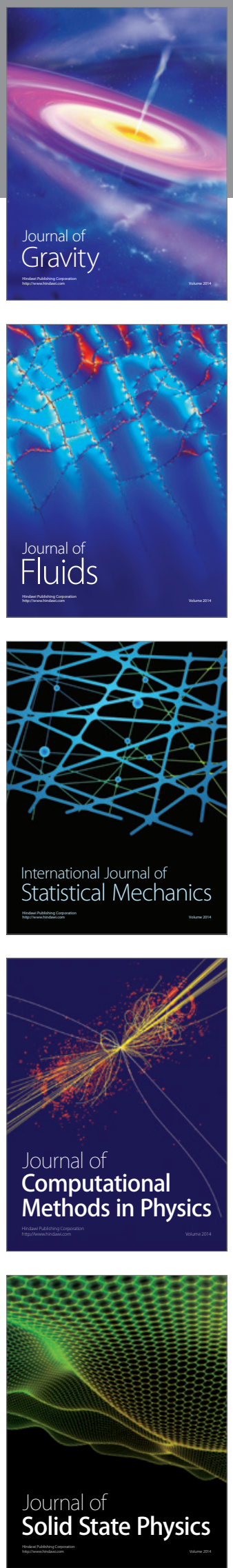

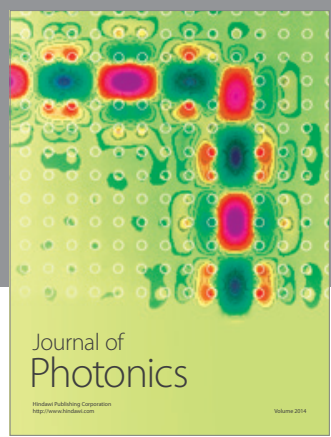

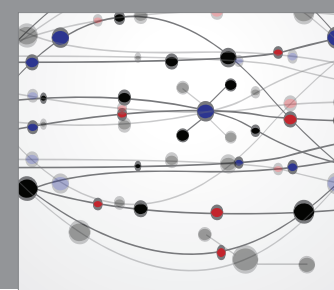

The Scientific World Journal

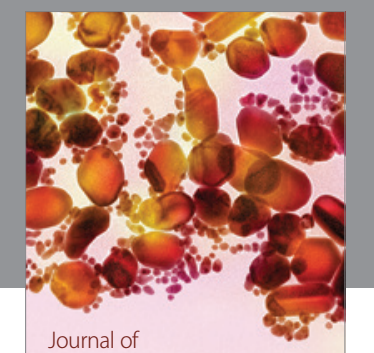

Soft Matter
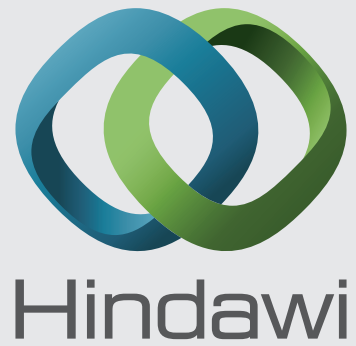

Submit your manuscripts at

http://www.hindawi.com
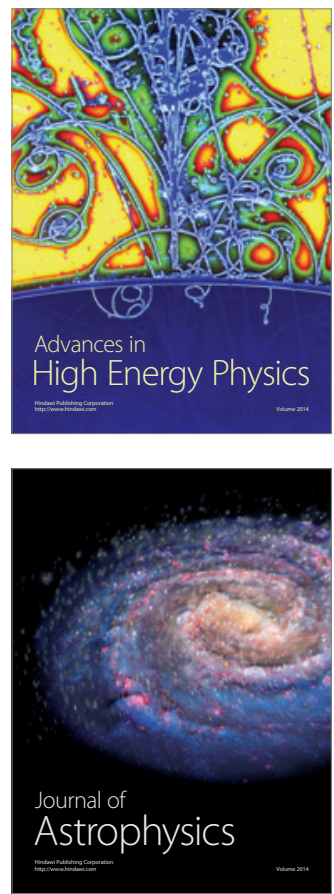
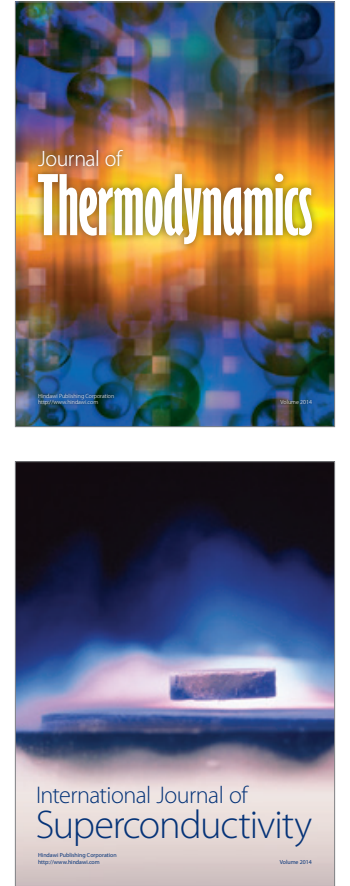
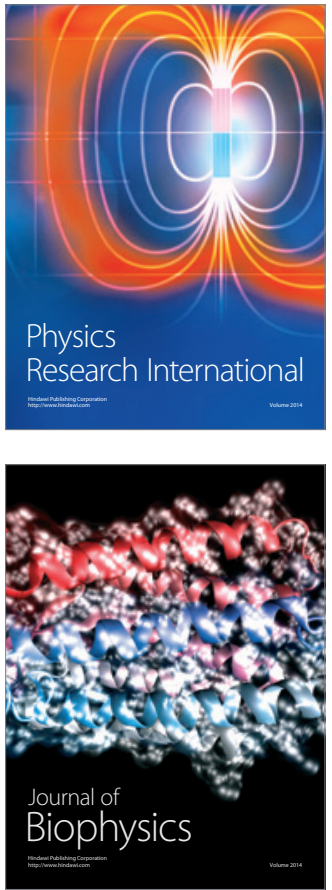
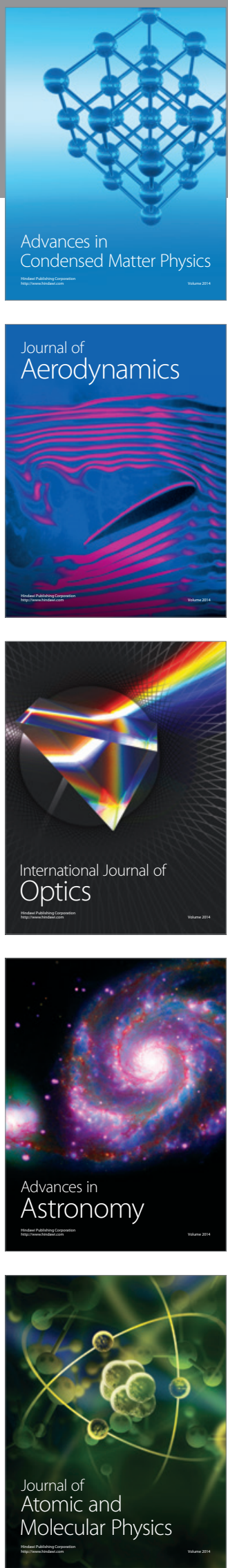